\title{
Article \\ A Cross-Sectional Survey Exploring the Impact of the COVID-19 Pandemic on the Cancer Care of Adolescents and Young Adults
}

\author{
Kaitlyn Howden ${ }^{1,+}$, Camille Glidden ${ }^{2,+}$, Razvan G. Romanescu ${ }^{3}$ D, Andrew Hatala ${ }^{4}$, Ian $\operatorname{Scott}^{5}$, \\ Julie Deleemans ${ }^{6}$ (D), Karine Chalifour ${ }^{7}$, Geoff Eaton ${ }^{7}$, Abha A. Gupta ${ }^{8,9}$, James M. Bolton ${ }^{2,10}$, \\ Alyson L. Mahar ${ }^{4,11}$, Sheila N. Garland 12 (D) and Sapna Oberoi 1,13,14,*(D)
}

check for

updates

Citation: Howden, K.; Glidden, C.; Romanescu, R.G.; Hatala, A.; Scott, I.; Deleemans, J.; Chalifour, K.; Eaton, G.; Gupta, A.A.; Bolton, J.M.; et al. A Cross-Sectional Survey Exploring the Impact of the COVID-19 Pandemic on the Cancer Care of Adolescents and Young Adults. Curr. Oncol. 2021, 28, 3201-3213. https://doi.org/10.3390/ curroncol28040278

Received: 17 July 2021

Accepted: 19 August 2021

Published: 22 August 2021

Publisher's Note: MDPI stays neutral with regard to jurisdictional claims in published maps and institutional affiliations.

Copyright: (c) 2021 by the authors. Licensee MDPI, Basel, Switzerland. This article is an open access article distributed under the terms and conditions of the Creative Commons Attribution (CC BY) license (https:/ / creativecommons.org/licenses/by/ $4.0 /)$.
1 Department of Pediatrics and Child Health, University of Manitoba, Winnipeg, MB R3A1S1, Canada; khowden2@manitoba-physicians.ca

2 Department of Psychiatry, University of Manitoba, Winnipeg, MB R3E3N4, Canada; cglidden@manitoba-physicians.ca (C.G.); JBOLTON@hsc.mb.ca (J.M.B.)

3 George \& Fay Yee Centre for Healthcare Innovation, University of Manitoba, Winnipeg, MB R3E0T6, Canada; Razvan.Romanescu@umanitoba.ca

4 Department of Community Health Sciences, Max Rady College of Medicine, University of Manitoba, Winnipeg, MB R3E0W3, Canada; Andrew.Hatala@umanitoba.ca (A.H.);

Alyson.Mahar@umanitoba.ca (A.L.M.)

5 Department of Psychosocial Oncology, CancerCare Manitoba, Winnipeg, MB R3E0V9, Canada; iscott@cancercare.mb.ca

6 Department of Psychosocial Oncology, University of Calgary Cumming School of Medicine, Calgary, AB T2N4N2, Canada; julie.deleemans@ucalgary.ca

7 Young Adult Cancer Canada, St. John's, NL A1A5B5, Canada; karine@youngadultcancer.ca (K.C.); geoff@youngadultcancer.ca (G.E.)

8 Princess Margaret Cancer Care Research Institute, Toronto, ON M5G2C1, Canada; abha.gupta@sickkids.ca

9 Department of Pediatric Hematology-Oncology, The Hospital for Sick Children, Toronto, ON M5G1X8, Canada

10 Manitoba Centre for Health Policy, University of Manitoba, Winnipeg, MB R3E3P5, Canada

11 Research Institute in Oncology and Hematology, CancerCare Manitoba, Winnipeg, MB R3E0V9, Canada

12 Department of Psychology, Memorial University, St. John's, NL A1C5S7, Canada; sheila.garland@mun.ca

13 Department of Pediatric Hematology-Oncology, CancerCare Manitoba, Winnipeg, MB R3E0V9, Canada

14 CancerCare Manitoba Research Institute, CancerCare Manitoba, Winnipeg, MB R3E0V9, Canada

* Correspondence: soberoi@cancercare.mb.ca; Tel.: +1-204-787-4163

+ These authors contributed equally to this work.

Abstract: We aimed to describe the negative and positive impacts of changes in cancer care delivery due to COVID-19 pandemic for adolescents and young adults (AYAs) in Canada, as well as the correlates of negative impact and their perspectives on optimization of cancer care. We conducted an online, self-administered survey of AYAs with cancer living in Canada between January and February 2021. Multiple logistic regression was used to identify factors associated with a negative impact on cancer care. Of the 805 participants, 173 (21.5\%) experienced a negative impact on their cancer care including delays in diagnostic tests (11.9\%), cancer treatment $(11.4 \%)$, and appointments $(11.1 \%)$. A prior diagnosis of mental or chronic physical health condition, an annual income of $<20,000$ CAD, ongoing cancer treatment, and province of residence were independently associated with a negative cancer care impact ( $p$-value $<0.05)$. The majority $(n=767,95.2 \%)$ stated a positive impact of the changes to cancer care delivery, including the implementation of virtual healthcare visits $(n=601$, $74.6 \%$ ). Pandemic-related changes in cancer care delivery have unfavorably and favorably influenced AYAs with cancer. Interventions to support AYAs who are more vulnerable to the adverse effects of the pandemic, and the thoughtful integration of virtual care into cancer care delivery models is essential.

Keywords: COVID-19; adolescents and young adults; cancer; oncology; virtual care; pandemic 


\section{Introduction}

COVID-19 is responsible for one of the largest global pandemics experienced in almost a century [1]. Individuals of all ages with a cancer diagnosis are particularly vulnerable to experiencing a multitude of adverse impacts secondary to the pandemic [2,3]. The enormous strain of COVID-19 on healthcare systems has significantly disrupted cancer care services worldwide, resulting in delayed diagnosis and treatment of patients with cancer and a reduction in their chances of survival [3-6]. Individuals with cancer are more prone to complications related to COVID-19 infection due to the underlying immune suppression and co-morbidities resulting from cancer and its treatment [7]. Guidelines on how to navigate the provision of healthcare during this pandemic have been rapidly changing and region specific, making it a challenging time for healthcare providers providing cancer care [8].

To combat the spread of the COVID-19 virus, most cancer care organizations have decreased the frequency of in-person appointments and diagnostic tests and shifted towards the provision of healthcare services through virtual platforms [3-6]. Alterations in cancer treatment protocols and access to clinical trials, medications, and physical or psychological support services have also raised concerns about the quality of cancer care during this pandemic $[6,8,9]$. Furthermore, it has become more challenging for patients to cope with their cancer given the personal disconnect they feel from healthcare providers and their social support system $[5,6]$.

Adolescents and young adults (AYAs) diagnosed with cancer between the ages of 15 and 39 years have felt the impact of shifting cancer care dynamics; their unique developmental, educational, social, and emotional needs may put them at a higher risk of experiencing adverse consequences of this pandemic [10]. A recently conducted online survey of 177 AYAs with cancer found that $45 \%$ of AYAs had their cancer care impacted by this pandemic, including delays in appointments and treatment and alterations to treatment protocols [11]. This survey included only 93 AYAs from North America and was conducted during an early phase of the pandemic. Furthermore, it did not identify the subgroups of AYAs that are more vulnerable to the negative cancer care impact or examine the perceived positive effects of changes to cancer care delivery during pandemic. Given the prolonged duration of this pandemic and the dynamic nature of public health restrictions, it is crucial to understand the cumulative effect of this pandemic on the cancer care of this population. Such data can help to address the current and future needs of AYAs with cancer.

Therefore, we sought to study the impact of the COVID-19 pandemic on AYAs with cancer (ICOVIDAYA) in Canada. Our analysis aimed to describe both the positive and negative impacts of the COVID-19 pandemic-related changes in cancer care delivery on AYAs with cancer, to identify the sociodemographic-, cancer-, and health-related factors associated with negative impacts, and to identify AYAs' perspectives on the optimization of cancer care during and after the pandemic.

\section{Methods}

We conducted a national, cross-sectional, self-administered online survey of AYAs living in Canada. All AYAs $\geq 18$ years old diagnosed with cancer between the ages 15 and 39 years and living in Canada at the time of survey completion were eligible for this study. For this particular analysis, we included the AYAs who were between 18 and 39 years of age at the time of completion of the survey. Questions of our survey were built upon a prior survey used for the Young Adults with Cancer in their Prime (YACPRIME) study and by reviewing the current literature [11,12]. The survey questionnaire underwent multiple iterations through virtual meetings with co-investigators and AYA cancer survivors. The final survey questionnaire contained 49 questions and required 10-15 min to complete. The select questions related to this analysis are listed in Supplementary Appendix A. We translated the final survey instrument into French and then back translated it into English for accuracy; the survey was offered in both official languages to the participants. The questionnaire domains pertaining to this analysis included sociodemographic and 
cancer-related information and the effects of the COVID-19 pandemic on cancer care. The University of Manitoba's Research Ethics Board approved this study (HS: 24501).

\subsection{Survey Administration}

This survey was created and administered online using REDCap, which is a secure web application [13]. A convenience sample of AYA participants were recruited across Canada by sharing the online survey link through social media sites of the Young Adult Cancer Canada (YACC) group and other Canadian AYA support groups, as well as through oncology clinics at CancerCare Manitoba. Patient partners also aided in disseminating our survey within their networks [12]. The survey was open for completion between January and February 2021. Informed consent was obtained online and was required before participating in the survey (Supplementary Appendix A). On completion of the survey, participants were offered a CAD 10 e-gift card. Contact details provided for this purpose were not linkable to the participants' survey responses.

\subsection{Survey Measures and Definitions}

\subsubsection{Measuring a Negative and Positive Impact on Cancer Care Delivery}

Participants were asked to rate the satisfaction of their cancer care during the pandemic using a 5-point Likert scale from very satisfied to very dissatisfied. A negative impact on cancer care was defined as a participant experiencing any of the following outcomes: changes to the treatment protocol; lack of access to clinical trials; delay or cancellation of appointments, diagnostic testing, or treatment; or limited access to supportive care resources such as mental health, spiritual therapy, physiotherapy, occupational therapy, and vocational rehabilitation. We did not consider changing in-person appointments to virtual appointments (phone-call, video-call, telehealth) as a negative impact. To assess the changes in cancer care delivery associated with a positive impact, participants were asked, "What changes in cancer care delivery during the pandemic have had a positive effect on you?". For this question, participants could select as many options as relevant from the options of, telephone visits, telehealth visits, videocall visits, delivery of cancer care closer to home, ability to communicate with healthcare providers by phone or email, and "other". Participants' perspectives on optimizing cancer care delivery during the pandemic were elicited through a free-text question, "How can cancer organizations provide optimal cancer care during this pandemic to adolescents and young adults with cancer?".

\subsubsection{Measuring Sociodemographic-, Cancer-, and Other Health-Related Information}

Sociodemographic data obtained from participants included age, gender (man/woman), province or territory of residence, geographic area (urban/rural/remote), race/ethnicity (white/non-white), relationship status (in a relationship/single), education status (full-time student/part-time student), employment status (employed/unemployed/disability or unemployment benefits), impact of COVID-19 on employment (yes/no), and personal income in the year 2020 in CAD $(<20,000 / 20,000-40,000 / 40,000-60,000 />60,000)$. Cancer-related information collected from participants included type of cancer diagnosis (hematologic vs. non-hematological), time since cancer diagnosis ( $<2$ years $/ 2$ to $<5$ years $/ \geq 5$ years) and presence of ongoing cancer treatment (yes/no). The participants self-reported the presence of a pre-pandemic mental illness such as anxiety, post-traumatic stress, and obsessivecompulsive or mood disorders. Participants stated current diagnoses of chronic physical health conditions, such as hypertension, diabetes, stroke, or other organ dysfunction, and this information was used to identify the presence of a chronic physical health condition (yes/no).

\subsubsection{Province or Territory of Residence}

Residential information was collapsed into five geographic regions: Central Canada (Ontario, Québec), Prairies (Alberta, Manitoba, Saskatchewan), British Columbia, Atlantic 
Canada (New Brunswick, Newfoundland and Labrador, Nova Scotia, Prince Edward Island), and Territories (Northwest Territories, Nunavut, Yukon).

\subsection{Statistical Analysis}

We summarized the sociodemographic-, cancer-, and other health-related data using descriptive statistics. Chi-square tests for independence and logistic regression were used to test associations between the pre-determined sociodemographic-, cancer-, and healthrelated variables and a negative impact on cancer care (yes/no). Odds ratios (OR) with associated $95 \%$ confidence intervals (CI) were used to report the associations. Using the Benjamin-Hochberg test for multiple testing, a $p$-value less than 0.03 was considered statistically significant for univariable analysis [14].

All variables were then included in a single multivariable logistic regression model to explore their independent associations with experiencing a negative impact on cancer care, adjusting for all other factors in the model. We excluded participants with one or more missing values for any of the multivariable logistic regression variables. Multicollinearity between dependent variables was assessed using the correlation matrix and variation inflation factor [15]. As a secondary analysis, we also examined the factors independently associated with a negative impact on cancer care for those on active cancer treatment compared to those who had completed cancer treatment using multiple logistic regression. All tests were two-sided, with a $p<0.05$ indicating statistical significance for multiple logistic regression. All the analyses were done using R software (version 4.0.0) [16].

\subsection{Qualitative Analysis}

Qualitative responses to an open-ended question on optimizing cancer care underwent summative content analysis [17]. We used Dedoose software (version: 8.3.47) for this analysis [18]. The codes were independently generated by KH and CG and were further refined by input from SO and $\mathrm{AH}$. During the initial coding, the data were read thoroughly to determine the underlying meaning being conveyed by respondents, and all possible ideas were created inductively from the data to preserve the participants' original meaning. We then pursued a set of central codes to all the excerpts during focused coding. The codes were organized into various categories during theoretical coding. The categories were refined throughout the analysis and were compared to one another using the constant comparative method to generate final themes [19].

\section{Results}

\subsection{Patient Demographics}

The survey was completed by 1063 participants, of which 805 were included in the analysis. We excluded 258 participants either because of age $>39$ years $(n=138)$ or not reporting their age $(n=120)$. Missing data were minimal $(0.1-2 \%)$. Table 1 summarizes the demographic and clinical characteristics of the study population. The mean age of participants was 30.3 years ( $\mathrm{SD}=5.3) ; 172(21.4 \%)$ were between 18 and 25 years of age. Most participants identified themselves as white $(n=770,95.6 \%)$ and lived in urban areas ( $n=605,75.5 \%)$. The most common cancer diagnosis was a solid tumor (non-brain tumors) $(n=615,76.4 \%)$. Most participants were less than five years from the time of cancer diagnosis $(n=667,82.8 \%)$, and one-third were receiving some form of cancer treatment $(n=265,33.0 \%)$. Pre-pandemic mental illness and chronic physical illness were reported by $17.8 \%(n=118)$ and $23.9 \%(n=192)$ of participants, respectively. Of the 805 included survey responses, 235 open-ended responses were provided totaling 2072 words. 
Table 1. Descriptive characteristics of the study population $(n=805)$.

\begin{tabular}{|c|c|c|}
\hline Variable & Mean \pm SD, or $n$ & $\%$ (Range) \\
\hline Age (in years) & $30.27 \pm 5.27$ & $(18-39)$ \\
\hline \multicolumn{3}{|l|}{ Gender $^{a}$} \\
\hline - Man & 445 & $55.50 \%$ \\
\hline - Woman & 357 & $44.50 \%$ \\
\hline - Non-Binary & 3 & $0.00 \%$ \\
\hline Ethnicity (White) & 770 & $95.60 \%$ \\
\hline Relationship Status (in a relationship) & 484 & $60.10 \%$ \\
\hline \multicolumn{3}{|l|}{ Province/Territory } \\
\hline - Prairies e & 233 & $28.90 \%$ \\
\hline - Central Canada ${ }^{f}$ & 222 & $27.60 \%$ \\
\hline - Atlantic $\mathrm{g}$ & 169 & $21.00 \%$ \\
\hline - Territories $\mathrm{h}$ & 93 & $11.60 \%$ \\
\hline - British Columbia & 88 & $10.90 \%$ \\
\hline \multicolumn{3}{|l|}{ Geographic Location ${ }^{b}$} \\
\hline - Urban & 605 & $75.50 \%$ \\
\hline - Rural & 179 & $22.30 \%$ \\
\hline - Remote & 17 & $2.10 \%$ \\
\hline \multicolumn{3}{|l|}{ Education Status ${ }^{c}$} \\
\hline - Part-time student & 24 & $3.00 \%$ \\
\hline - Full-time student & 75 & $9.30 \%$ \\
\hline \multicolumn{3}{|l|}{ Employment Status ${ }^{\mathrm{c}}$} \\
\hline - Employed (part or full time) & 562 & $70.00 \%$ \\
\hline - Unemployed & 103 & $12.80 \%$ \\
\hline - Disability or unemployment benefits & 32 & $4.00 \%$ \\
\hline - Other ${ }^{\mathrm{i}}$ & 51 & $6.30 \%$ \\
\hline \multicolumn{3}{|l|}{ Personal Income in year $2020^{j}$} \\
\hline$-<\$ 20,000$ & 57 & $7.10 \%$ \\
\hline - $\$ 20,000$ to $<\$ 40,000$ & 115 & $14.30 \%$ \\
\hline - $\$ 40,000$ to $<\$ 60,000$ & 195 & $24.30 \%$ \\
\hline$-\geq \$ 60,000$ & 389 & $48.40 \%$ \\
\hline Pre-pandemic mental health condition (yes) ${ }^{d}$ & 118 & $14.80 \%$ \\
\hline \multicolumn{3}{|l|}{$\begin{array}{l}\text { Type of pre-pandemic mental health } \\
\text { condition } d\end{array}$} \\
\hline - Anxiety disorder & 75 & $9.40 \%$ \\
\hline - Mood disorder & 65 & $8.10 \%$ \\
\hline - Other $\mathrm{k}$ & 4 & $0.50 \%$ \\
\hline $\begin{array}{l}\text { Presence of a chronic physical health } \\
\text { condition (yes) }\end{array}$ & 192 & $23.90 \%$ \\
\hline \multicolumn{3}{|l|}{ Type of chronic physical condition } \\
\hline - Hypertension or Diabetes & 89 & $11.00 \%$ \\
\hline - Lung or Heart Disease & 59 & $7.30 \%$ \\
\hline - Kidney or Liver Disease & 58 & $7.20 \%$ \\
\hline - Other ${ }^{1}$ & 22 & $2.70 \%$ \\
\hline \multicolumn{3}{|l|}{ Cancer type } \\
\hline - Hematological malignancies & 155 & $19.30 \%$ \\
\hline - Solid tumors (non-brain tumors) & 615 & $76.40 \%$ \\
\hline - Brain tumors & 35 & $4.30 \%$ \\
\hline
\end{tabular}


Table 1. Cont.

\begin{tabular}{|c|c|c|}
\hline Variable & Mean $\pm \mathrm{SD}$, or $n$ & $\%$ (Range) \\
\hline \multicolumn{3}{|l|}{ Time since cancer diagnosis } \\
\hline$-<2$ years & 246 & $30.50 \%$ \\
\hline-2 years to $<5$ years & 421 & $52.20 \%$ \\
\hline$-\geq 5$ years & 138 & $17.10 \%$ \\
\hline Currently receiving cancer treatment (yes) ${ }^{\mathrm{C}}$ & 265 & $33.00 \%$ \\
\hline \multicolumn{3}{|l|}{$\begin{array}{l}\text { Negative impact of COVID-19 pandemic on } \\
\text { cancer care }\end{array}$} \\
\hline - Yes & 173 & $21.50 \%$ \\
\hline - No & 632 & $78.50 \%$ \\
\hline
\end{tabular}

\subsection{Impact of COVID-19 Pandemic on Cancer Care}

Overall, $76.6 \%$ reported being satisfied with their cancer care during the pandemic ( $n=617)$. In total, 173 participants $(21.5 \%)$ experienced a negative impact on their cancer care due to the pandemic. Among those receiving active cancer treatment $(n=265)$, $27.2 \%(n=72)$ encountered a negative impact on their cancer care. Overall, the most common negative impacts were delays or cancellations in either appointments $(n=131$, $16.2 \%)$ diagnostic testing $(n=96,11.9 \%)$, or treatment $(n=92,11.4 \%)$ (Figure 1$)$. Of those experiencing a negative impact, $156(19.4 \%), 103(12.8 \%)$, and $49(6.1 \%)$ experienced at least one, two, and three of these impacts, respectively. Almost all participants experienced positive impacts due to pandemic-related changes to the delivery of their cancer care ( $n=767,95.2 \%)$. Three-quarters of the participants $(n=601,74.6 \%)$ responded that virtual visits had a positive impact on them, particularly the video call visits $(n=357,44.3 \%)$ and telehealth visits $(n=368,45.7 \%)$ (Figure 2). Receiving cancer care closer to home $(n=217$, $28.6 \%$ ) and the ability to communicate with healthcare providers outside of appointments via phone calls $(n=217,27.0 \%)$ and emails $(n=98,12.2 \%)$ also positively influenced cancer care (Figure 2).

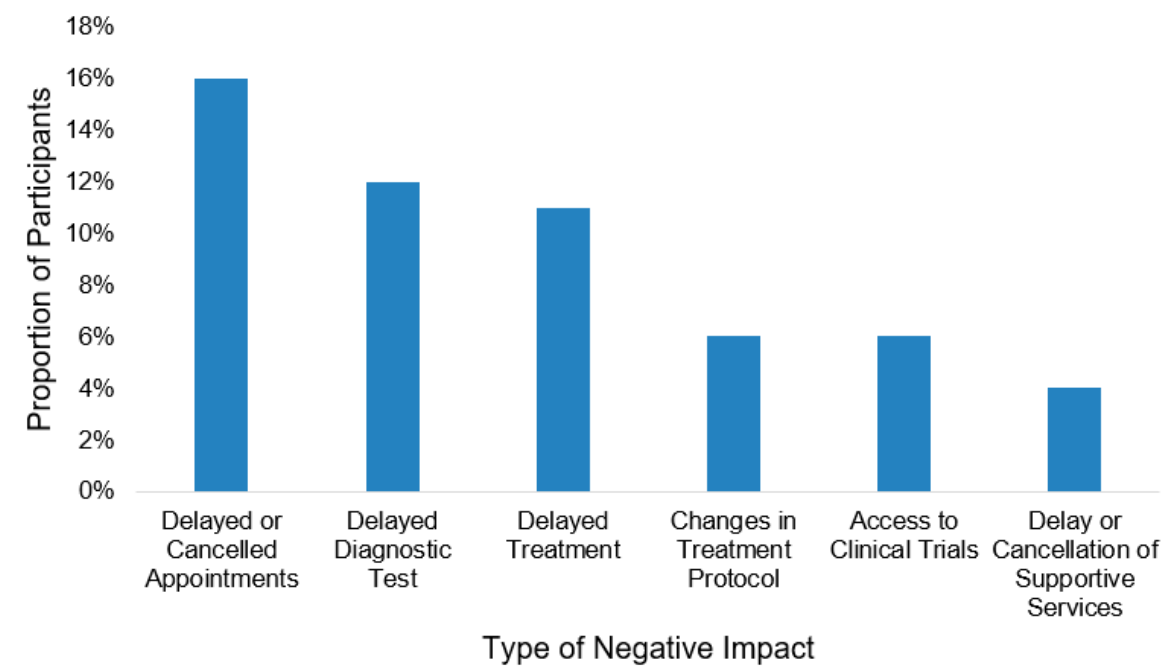

Figure 1. Type of negative impact of the COVID-19 pandemic on cancer care $(n=173)$. 


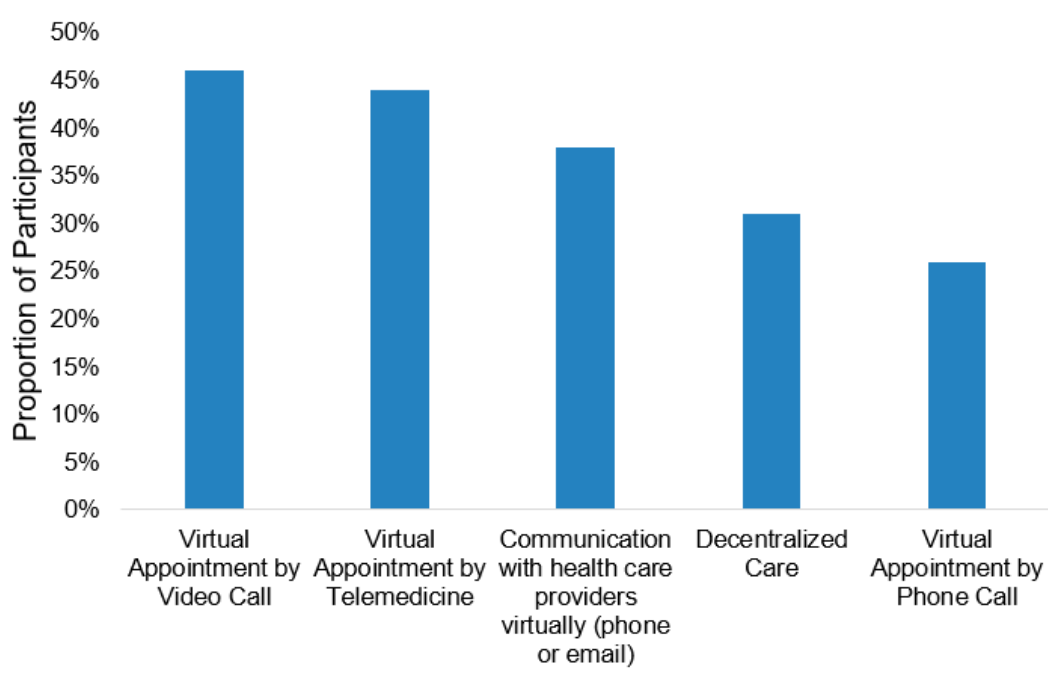

Figure 2. Changes in cancer care delivery associated with a positive impact $(n=767)$.

\subsection{Factors Associated with a Negative Impact of COVID-19 Pandemic on Cancer Care}

On univariable analyses, woman gender, province/territory of residence, pre-pandemic mental illness or chronic physical health condition, and ongoing cancer treatment were associated with experiencing at least one negative impact on cancer care $(p<0.03)$. After excluding 98 individuals due to variable selection, 707 participants were included in the multivariable regression. A pre-existing mental illness ( $\mathrm{OR}=12.14,95 \% \mathrm{CI} 6.98-21.66, p<0.001)$, having a chronic physical health condition (OR $=2.22,95 \% \mathrm{CI} 1.34-3.67, p=0.002)$, personal income $<20,000 \mathrm{CAD}$ in the year 2020 (OR =4.21,95\% CI 2.03-8.75), and ongoing cancer treatment $(\mathrm{OR}=1.69,95 \%$ CI 1.03-2.77, $p=0.036)$ were independently associated with a negative impact on cancer care (Table 2 ). The odds of having a negative impact on cancer care were also higher among participants from Central Canada $(\mathrm{OR}=8.43,95 \% \mathrm{CI}$ 2.90-32.03, $p<0.001$ ), the Prairies (OR $=4.52,95 \%$ CI 1.54-17.13, $p=0.012$ ), and British Columbia $(\mathrm{OR}=6.74,95 \%$ CI 2.05-27.63, $p=0.0034)$ when compared to those living in the Territories of Canada.

Table 2. Factors associated with a negative impact of the COVID-19 pandemic on cancer care delivery.

\begin{tabular}{|c|c|c|c|c|c|c|}
\hline & \multicolumn{3}{|c|}{ Univariable Analysis $(n=805)$} & \multicolumn{3}{|c|}{ Multivariable Analysis $(n=707)$} \\
\hline & $\begin{array}{c}\text { Adjusted Odds } \\
\text { Ratio }\end{array}$ & $\begin{array}{c}95 \% \text { CI } \\
\text { (Lower-Upper) }\end{array}$ & $p$-Value & $\begin{array}{c}\text { Adjusted Odds } \\
\text { Ratio }\end{array}$ & $\begin{array}{c}95 \% \text { CI } \\
\text { (Lower, Upper) }\end{array}$ & $p$-Value \\
\hline $\begin{array}{l}\text { Age } \\
->25 \text { years } \\
-<18-25 \text { years }\end{array}$ & $\begin{array}{l}0.72 \\
\text { (ref) }\end{array}$ & $0.49-1.07$ & 0.102 & $\begin{array}{l}0.98 \\
\text { (ref) }\end{array}$ & $0.94-1.03$ & 0.431 \\
\hline $\begin{array}{l}\text { Gender }^{a} \\
\text { - Woman } \\
\text { - Man }\end{array}$ & $\begin{array}{l}1.73 \\
\text { (ref) }\end{array}$ & $1.23-2.43$ & 0.001 & $\begin{array}{l}1.41 \\
\text { (ref) }\end{array}$ & $0.90-2.20$ & 0.13 \\
\hline $\begin{array}{l}\text { Ethnicity } \\
\text { - Non-White } \\
\text { - White }\end{array}$ & $\begin{array}{l}1.8 \\
\text { (ref) }\end{array}$ & $0.83-3.89$ & 0.133 & $\begin{array}{l}2.07 \\
\text { (ref) }\end{array}$ & $0.76-5.52$ & 0.147 \\
\hline $\begin{array}{l}\text { Province/Territory } \\
\text { - Central Canada } \mathrm{e} \\
\text { - Prairies } \mathrm{f} \\
\text { - British Columbia } \\
\text { - Atlantic Canada } \mathrm{g} \\
\text { - Territories } \mathrm{h}\end{array}$ & $\begin{array}{l}9.41 \\
7.37 \\
8.83 \\
2.99 \\
\text { (ref) }\end{array}$ & $\begin{array}{c}3.32-26.69 \\
2.59-20.96 \\
2.93-26.62 \\
0.99-9.02\end{array}$ & $<0.001$ & $\begin{array}{l}8.43 \\
4.52 \\
6.74 \\
2.54 \\
\text { (ref) }\end{array}$ & $\begin{array}{l}2.90-32.03 \\
1.54-17.13 \\
2.05-27.63 \\
0.79-10.14\end{array}$ & $\begin{array}{c}<0.001 \\
0.012 \\
0.003 \\
0.144\end{array}$ \\
\hline $\begin{array}{l}\text { Geographic Location }{ }^{b} \\
\text { - Rural } \\
\text { - Remote } \\
\text { - Urban }\end{array}$ & $\begin{array}{l}1.4 \\
0.52 \\
\text { (ref) }\end{array}$ & $\begin{array}{l}0.95-2.06 \\
0.12-2.32\end{array}$ & 0.146 & $\begin{array}{l}1.06 \\
0.69 \\
\text { (ref) }\end{array}$ & $\begin{array}{l}0.63-1.76 \\
0.09-3.12\end{array}$ & $\begin{array}{l}0.815 \\
0.661\end{array}$ \\
\hline
\end{tabular}


Table 2. Cont.

\begin{tabular}{|c|c|c|c|c|c|c|}
\hline & \multicolumn{3}{|c|}{ Univariable Analysis $(n=805)$} & \multicolumn{3}{|c|}{ Multivariable Analysis $(n=707)$} \\
\hline & $\begin{array}{c}\text { Adjusted Odds } \\
\text { Ratio }\end{array}$ & $\begin{array}{c}95 \% \text { CI } \\
\text { (Lower-Upper) }\end{array}$ & $p$-Value & $\begin{array}{c}\text { Adjusted Odds } \\
\text { Ratio }\end{array}$ & $\begin{array}{c}95 \% \text { CI } \\
\text { (Lower, Upper) }\end{array}$ & $p$-Value \\
\hline $\begin{array}{l}\text { Income in year } 2020^{i} \\
-<\$ 20,000 \\
\text { - } \$ 20,000 \text { to }<\$ 40,000 \\
\text { - } \$ 40,000 \text { to }<\$ 60,000 \\
\text { - } \$ 60,000+\end{array}$ & $\begin{array}{l}4.34 \\
1.51 \\
1.51 \\
\text { (ref) }\end{array}$ & $\begin{array}{l}2.41-7.80 \\
0.90-2.53 \\
0.98-2.32\end{array}$ & $<0.001$ & $\begin{array}{l}4.21 \\
0.89 \\
1.17 \\
\text { (ref) }\end{array}$ & $\begin{array}{l}2.03-8.75 \\
0.45-1.72 \\
0.67-2.00\end{array}$ & $\begin{array}{c}<0.001 \\
0.732 \\
0.583\end{array}$ \\
\hline $\begin{array}{l}\text { Pre-pandemic mental health } \\
\text { condition }{ }^{\mathrm{d}} \\
\text { - Yes } \\
\text { - No }\end{array}$ & $\begin{array}{l}10.93 \\
\text { (ref) }\end{array}$ & 7.08-16.88 & $<0.001$ & $\begin{array}{l}12.14 \\
\text { (ref) }\end{array}$ & $6.98-21.66$ & $<0.001$ \\
\hline $\begin{array}{l}\text { Presence of a chronic } \\
\text { physical health condition }{ }^{\mathrm{d}} \\
\text { - Yes } \\
\text { - No }\end{array}$ & $\begin{array}{l}2.71 \\
\text { (ref) }\end{array}$ & $1.88-3.92$ & $<0.001$ & $\begin{array}{l}2.22 \\
\text { (ref) }\end{array}$ & $1.34-3.67$ & 0.002 \\
\hline $\begin{array}{l}\text { Time since cancer diagnosis } \\
-<2 \text { years } \\
-2 \text { to }<5 \text { years } \\
-\geq 5 \text { years }\end{array}$ & $\begin{array}{l}0.9 \\
1.21 \\
\text { (ref) }\end{array}$ & $\begin{array}{l}0.53-1.53 \\
0.75-1.94\end{array}$ & 0.32 & $\begin{array}{l}1.08 \\
1.23 \\
\text { (ref) }\end{array}$ & $\begin{array}{l}0.53-2.24 \\
0.65-2.39\end{array}$ & $\begin{array}{c}0.84 \\
0.529\end{array}$ \\
\hline $\begin{array}{l}\text { Cancer type } \\
\text { - Hematologic } \\
\text { - Non-hematologic }\end{array}$ & $\begin{array}{l}0.95 \\
\text { (ref) }\end{array}$ & $0.61-1.48$ & 0.828 & $\begin{array}{l}0.83 \\
\text { (ref) }\end{array}$ & $0.43-1.54$ & 0.569 \\
\hline $\begin{array}{l}\text { Currently receiving cancer } \\
\text { treatment }{ }^{c} \\
\text { - Yes } \\
\text { - No }\end{array}$ & $\begin{array}{l}1.1 \\
\text { (ref) }\end{array}$ & $0.77-1.57$ & 0.596 & $\begin{array}{l}1.69 \\
\text { (ref) }\end{array}$ & $1.03-2.77$ & 0.036 \\
\hline
\end{tabular}

${ }^{\mathrm{a}} n=802$ for univariable analysis; ${ }^{\mathrm{b}} n=801$ for univariable analysis; ${ }^{\mathrm{c}} n=803$ for univariable analysis; ${ }^{\mathrm{d}} n=800$ for univariable analysis,

e Ontario, Quebec; ${ }^{\mathrm{f}}$ Alberta, Manitoba, Saskatchewan ${ }^{\mathrm{g}}$ Newfoundland and Labrador, Nova Scotia, New Brunswick, Prince Edward Island;

h Yukon, Northwest Territories, Nunavut; ${ }^{i}$ in Canadian Dollars; ${ }^{j}$ Solid tumors and brain tumors.

When comparing the multivariable regression analyses examining the independent factors associated with a negative impact on cancer care for those on active cancer treatment to those off treatment, the presence of a pre-existing mental illness, Province/Territory of residence, and a personal income $<20,000$ CAD in the year 2020 remained statistically significant for both groups (Tables S1 and S2). While the presence of a pre-pandemic chronic physical health condition was significant for those on active cancer treatment $(\mathrm{OR}=6.88,95 \% \mathrm{CI} 2.18-22.14, p=0.001)$, it was not statistically significant for those who had completed treatment $(\mathrm{OR}=1.40,95 \%$ CI $0.75-2.57, p=0.281)$. Significance of gender also differed between the two groups; being a woman was independently associated with a negative impact on cancer care for those belonging to the completed treatment group $(\mathrm{OR}=2.22,95 \% \mathrm{CI} 1.30-3.82, p=0.004)$ but not for those in the active treatment group $(\mathrm{OR}=0.76,95 \%$ CI $0.28-1.94, p=0.567)$.

\subsection{Optimization of Cancer Care}

Table 3 contains the common themes and subthemes and relevant excerpts that emerged from participants' responses $(n=235,29.2 \%)$ on how cancer care could be optimized during the pandemic. The main themes included improving healthcare visits, enhancing personalized care, improving prevention of COVID-19, addressing information needs, and avoiding diagnostic and treatment delays. The majority wanted the continuation of virtual care, including increased opportunities to connect with their healthcare team via emails and phone calls. 
Table 3. Themes and subthemes of optimization of cancer care during the COVID-19 pandemic ( $n=235$ excerpts).

\begin{tabular}{|c|c|c|}
\hline Theme & Definition & Examples of Excerpts \\
\hline \multicolumn{3}{|c|}{ Improving Healthcare Visits (37\%) } \\
\hline $\begin{array}{l}\text { Increased ability to make } \\
\text { appointments in advance (flexible }\end{array}$ & \multirow{3}{*}{$\begin{array}{l}\text { Descriptions of ways care could best be } \\
\text { arranged or facilitated by } \\
\text { healthcare providers }\end{array}$} & $\begin{array}{l}\text { "Make it easier to contact doctors/nurses } \\
\text { through email/video calls" }\end{array}$ \\
\hline More virtual appointments & & $\begin{array}{l}\text { "Easier access to doctors regarding } \\
\text { appointments and bookings so that calls don't go } \\
\text { weeks with no response" }\end{array}$ \\
\hline $\begin{array}{l}\text { Providing care closer to home } \\
\text { (decentralized care) }\end{array}$ & & "Offers on-site therapy as well as telemedicine" \\
\hline \multicolumn{3}{|c|}{ Enhancing Personalized Care $(18 \%)$} \\
\hline $\begin{array}{l}\text { Good communication from } \\
\text { cancer organizations }\end{array}$ & \multirow{3}{*}{$\begin{array}{l}\text { Ideas about how their experience could } \\
\text { be enhanced to support their wellbeing } \\
\text { by healthcare teams }\end{array}$} & "Listen to us and do not ignore our symptoms" \\
\hline $\begin{array}{l}\text { Caring for and encouraging } \\
\text { patients (compassion } \\
\text { and validation) } \\
\text { Access to physical rehabilitation }\end{array}$ & & $\begin{array}{l}\text { "Continue to provide support services (as } \\
\text { opposed to cancelling and closing most services } \\
\text { during the pandemic)" }\end{array}$ \\
\hline Increased mental health supports & & $\begin{array}{l}\text { "Having access to support for mental health, } \\
\text { coping, pain management" }\end{array}$ \\
\hline \multicolumn{3}{|c|}{ Improving Prevention of COVID-19 (15\%) } \\
\hline Physical distancing & \multirow{2}{*}{$\begin{array}{l}\text { Suggestions on ways individuals and } \\
\text { healthcare centers can prevent spreading } \\
\text { or contracting COVID-19 }\end{array}$} & $\begin{array}{l}\text { "We should not go to places where people gather. } \\
\text { If we can not go out, we should not go out" } \\
\text { "Reduce the number of visits to the hospital" }\end{array}$ \\
\hline $\begin{array}{l}\text { Use of protective equipment } \\
\text { and practices }\end{array}$ & & "Wash your hands frequently and wear a mask" \\
\hline \multicolumn{3}{|c|}{ Addressing Information Needs (13\%) } \\
\hline COVID-19-specific information & $\begin{array}{l}\text { Statements describing optimal ways to } \\
\text { receive information related to cancer care, } \\
\text { self-care, or how the COVID-19 pandemic } \\
\text { affects them specifically as a population }\end{array}$ & $\begin{array}{l}\text { "Reach out to cancer patients directly with } \\
\text { information on how the pandemic affects our } \\
\text { particular cases" } \\
\text { "Provide digital resources or connections at } \\
\text { home (e.g., how to stay healthy and active)" } \\
\text { "Cancer organizations provide better care by } \\
\text { including information on the site" }\end{array}$ \\
\hline \multicolumn{3}{|c|}{ Avoiding Diagnostic and Treatment Delays (11\%) } \\
\hline $\begin{array}{l}\text { Delay in diagnosis } \\
\text { Delay in treatment }\end{array}$ & $\begin{array}{l}\text { Statements highlighting the importance } \\
\text { of not delaying diagnostic tests, } \\
\text { appointments, and treatment protocols }\end{array}$ & $\begin{array}{c}\text { "COVID should have NO impact on testing and } \\
\text { treatment, and care providers should be very } \\
\text { open about why appointments are } \\
\text { being rescheduled" } \\
\text { "Do not delay follow-up appointments, } \\
\text { treatments, or exams" }\end{array}$ \\
\hline
\end{tabular}

"Provide telephone and network consultation services to reduce the number of visits to the hospital and increase the function of making an appointment in advance."

Many patients reported they preferred virtual options with a video component as it helped them feel more connected to their healthcare provider and reduced their fear of missing their health issues compared to phone visits.

"Need more access electronically to supports (texts, email, etc.), would like access to test results, I think video chat is better than phone calls."

Whereas some participants wanted the ability to choose between in-person and virtual appointments and favored in-person visits over virtual visits:

"I think telephone and virtual appointments are only helpful for some people and should not be a catchall. I would prefer to see more in-person options for those that are struggling." 
The participants also expressed a desire for their healthcare team to provide more educational resources related to their cancer care, self-care, and navigating the COVID19 pandemic as a patient with cancer. Some participants highlighted that their concerns were not being listened to or addressed and that their healthcare teams must improve communication.

\section{Discussion}

Our cross-sectional study highlighted both negative and positive aspects of how the COVID-19 pandemic modified cancer care delivery to AYAs with cancer in Canada. To our knowledge, this is the first Canadian study to assess in detail how the pandemic has impacted multiple aspects of cancer care of AYAs with cancer and to identify factors that place certain AYAs with cancer at greater risk for experiencing the negative impact of this pandemic.

We found that the pandemic unfavorably altered the cancer care of one-fifth of AYAs diagnosed with cancer. Notably, other studies have reported higher rates (30-50\%) of the negative impact of the pandemic on cancer care [20-22]. These differential findings are likely attributable to the lower number of patients receiving active cancer treatment in our study compared to other studies and the different geographic locations, waves of the pandemic, and healthcare systems between the studies [11,20-22].

In our study, the most frequently experienced negative impacts on care were delays or cancellations in diagnostic tests, treatment, or healthcare visits. These findings are congruent with other studies demonstrating a similar spectrum of pandemic-related delays in diagnosis and staging, initiation of therapy, and interruption of ongoing treatment and clinical research [3-6]. AYAs with pre-existing mental health or chronic physical health conditions were at the highest risk of having a negative impact. AYAs with comorbid physical and mental health conditions may worry more about acquiring the COVID-19 infection than others and might be more hesitant to visit hospitals [11]. The COVID-19 pandemic has further increased the levels of distress for those with pre-existing mental health conditions by diminishing access to mental health support and the typical coping strategies such as family and friend support systems [23,24]. Those with chronic health conditions and limited support may face increased difficulties accessing and navigating their cancer care during the pandemic [25]. Those in the active phase of treatment typically require more frequent visits to the hospital than those who are off treatment, and this may explain why a chronic health condition had more of a negative impact on cancer care for this subgroup of AYAs.

We found that participants in the lowest income bracket $(<20,000$ CAD) were also at an elevated risk of encountering an adverse impact on their cancer care compared to others, even in Canada's publicly insured healthcare system. Pre-pandemic studies have shown disparities in cancer care for socioeconomically disadvantaged individuals [26]. These individuals have also been disproportionally affected by this pandemic in different ways, including having a higher likelihood of being employed in jobs that do not provide the option of working from home or of paid leaves [27]. Access to cancer care may also be challenging for this subgroup of patients because of not having the safe and reliable means to travel to appointments or the inability to access virtual platforms used for cancer care delivery during pandemic [24]. We also observed different experiences of negative impacts on cancer care across the provinces and territories in Canada. The substantial variability in COVID-19 infection and mortality and public health restrictions across Canada may have influenced cancer care delivery differently across the country [27].

When comparing factors that had a negative impact on cancer care between those actively receiving treatment and those off therapy, identifying as a woman was only significant for the off-therapy group. One possible explanation for this is that those who have completed treatment were often considered better candidates to receive part of their ongoing follow-up care through virtual care during this pandemic. While most studies have found that gender does not play a significant role in determining satisfaction with 
telemedicine appointments, one recent retrospective cohort study looking at appointments conducted during the pandemic found that women experienced lower patient satisfaction during virtual visits as compared to men [28-32]. The lower satisfaction level with virtual appointments during the survivorship period might have been perceived as having a negative impact on their overall cancer care by women.

Despite the disruptions in cancer care, most AYAs reported positive effects resulting from the virtual care and increased decentralization of cancer care during the pandemic. In particular, virtual care with a video element was favored by most. Virtual healthcare has many benefits, including increasing safety for healthcare providers and patients by allowing for connectivity from a distance and increasing the accessibility for those who struggle to attend in-person appointments due to location or time constraints [33]. While the concept of virtual care is not new in oncology, the widespread delivery of virtual care increased significantly during pandemic to protect patients from COVID-19 infection [34]. Although most participants in our study wanted to include some form of video calls or telehealth into their cancer care, this was not a desirable option for all. Integrating virtual care into routine cancer care must be based on each patient's values and preferences and should be the focus of future research; it should not increase the inequalities in cancer care due to the existing digital divide.

Some limitations of our study deserve attention. Most participants completing the survey were white, identified as men or women, and were from urban areas. As a result, our survey does not capture cancer care delivery experiences of Black or Indigenous AYAs, AYAs of color, gender diverse AYAs, and those living in remote geographical locations. More research and outreach are needed to traditionally underserved AYA cancer populations to understand their care experiences during the pandemic and ensure their perspectives are included in optimizing cancer care moving forward. Since we only surveyed AYAs with cancer in Canada, our findings may not be generalizable to those living in other countries with different healthcare systems and varying pandemic severity. Although not classified as having a negative impact, virtual care might have unfavorably affected some AYAs, as was apparent from the qualitative data. Our survey also might have inflated the positive influence of virtual care by selecting individuals with access to the technology required for completing this online survey. Finally, ascertainment of pre-existing mental and physical health conditions was based on self-reporting and is subject to social desirability bias [35].

Despite these limitations, our study has several strengths. Our study captured the impact of the pandemic on cancer care of AYAs with cancer who have unique needs and experiences compared to other cancer populations. A large and diverse sample size of AYAs with various cancer diagnoses from different geographical locations across the province participated in our survey. Besides collecting quantitative data, we also received diverse qualitative responses from study participants. The qualitative responses provided more depth and richness to our understanding of the pandemic's impact and corroborated our quantitative findings [36]. Insights gained from these patient experiences can provide further guidance on the strategies needed to improve the quality of life and healthcare delivery to AYAs with cancer throughout the remainder of the pandemic and into the post-pandemic era.

In conclusion, despite the remarkable feats of adaptation by cancer organizations to provide essential care during this pandemic, one in five AYAs in Canada experienced a negative impact on their cancer care delivery. Those with pre-existing mental and chronic physical health diagnoses require additional strategies to navigate cancer care during the pandemic. Greater advocacy and supports are essential for socioeconomically disadvantaged individuals to assure equitable access to cancer care. Thoughtful integration of virtual care into ambulatory care can improve cancer care delivery to AYAs even in the post-pandemic landscape. 
Supplementary Materials: The following are available online at https:/ / www.mdpi.com/article / 10.3390 / curroncol28040278/s1, Supplemental Appendix A: Informed consent and survey questions applicable to analysis of impact of COVID-19 pandemic on cancer care of AYAs with cancer; Table S1: Factors associated with a negative impact on cancer care among the participants receiving active cancer treatment $(n=265)$; Table S2: Factors associated with a negative impact on cancer care among the participants who had completed cancer treatment $(n=538)$.

Author Contributions: Conceptualization: All authors; Methodology: All authors; Software: R.G.R., K.H., C.G., and S.O.; Formal Analysis: R.G.R., K.H., C.G., A.H., and S.O.; Data Curation: R.G.R.; Writing-Original Draft Preparation: K.H., C.G., and S.O.; Writing-Review and Editing: K.H. and S.O.; Visualization: K.H., C.G., and S.O.; Supervision: S.O.; Project Administration: S.O.; Funding Acquisition: S.O. All authors have read and agreed to the published version of the manuscript.

Funding: This work was funded by CancerCare Manitoba Foundation (Grant number: 764135447).

Institutional Review Board Statement: The study was performed in accordance with the Declaration of Helsinki. Ethics was provided by the University of Manitoba's Research Ethics Board (HS: 24501).

Informed Consent Statement: Informed consent was obtained online from all participants prior to survey completion.

Data Availability Statement: The datasets generated during and/or analyzed during the current study are available from the corresponding author on reasonable request.

Acknowledgments: We thank our study participants and patient partners for their contribution to this study.

Conflicts of Interest: No conflicts of interest to declare.

\section{References}

1. Petersen, E.; Koopmans, M.; Go, U.; Hamer, D.H.; Petrosillo, N.; Castelli, F.; Storgaard, M.; Al Khalili, S.; Simonsen, L. Comparing SARS-CoV-2 with SARS-CoV and influenza pandemics. Lancet Infect. Dis. 2020, 20, e238-e244. [CrossRef]

2. Graetz, D.; Agulnik, A.; Ranadive, R.; Vedaraju, Y.; Chen, Y.; Chantada, G.; Metzger, M.L.; Mukkada, S.; Force, L.M.; Friedrich, P.; et al. Global effect of the COVID-19 pandemic on paediatric cancer care: A cross-sectional study. Lancet Child Adolesc. Health 2021, 5, 332-340. [CrossRef]

3. Kutikov, A.; Weinberg, D.S.; Edelman, M.; Horwitz, E.M.; Uzzo, R.G.; Fisher, R.I. A War on Two Fronts: Cancer Care in the Time of COVID-19. Ann. Intern. Med. 2020, 172, 756-758. [CrossRef]

4. Jazieh, A.R.; Akbulut, H.; Curigliano, G.; Rogado, A.; Alsharm, A.A.; Razis, E.D.; Mula-Hussain, L.; Errihani, H.; Khattak, A.; De Guzman, R.B.; et al. Impact of the COVID-19 Pandemic on Cancer Care: A Global Collaborative Study. JCO Glob. Oncol. 2020, 6, 1428-1438. [CrossRef] [PubMed]

5. Moraliyage, H.; De Silva, D.; Ranasinghe, W.; Adikari, A.; Alahakoon, D.; Prasad, R.; Lawrentschuk, N.; Bolton, D. Cancer in Lockdown: Impact of the COVID-19 Pandemic on Patients with Cancer. Oncologist 2020, 26, 342-344. [CrossRef]

6. Constantinou, C.; Kolokotroni, O.; Mosquera, M.; Heraclides, A.; Demetriou, C.; Karayiannis, P.; Quattrocchi, A.; Charalambous, A. Developing a holistic contingency plan: Challenges and dilemmas for cancer patients during the COVID-19. Cancer Med. 2020, 9, 6082-6092. [CrossRef] [PubMed]

7. Fung, M.; Babik, J.M. COVID-19 in Immunocompromised Hosts: What We Know So Far. Clin. Infect. Dis. 2020, 72, 340-350. [CrossRef] [PubMed]

8. Jazieh, A.R.; Chan, S.L.; Curigliano, G.; Dickson, N.; Eaton, V.; Garcia-Foncillas, J.; Gilmore, T.; Horn, L.; Kerr, D.J.; Lee, J.; et al. Delivering Cancer Care during the COVID-19 Pandemic: Recommendations and Lessons Learned from ASCO Global Webinars. JCO Glob. Oncol. 2020, 6, 1461-1471. [CrossRef]

9. Wang, Y.; Duan, Z.; Ma, Z.; Mao, Y.; Li, X.; Wilson, A.; Qin, H.; Ou, J.; Peng, K.; Zhou, F.; et al. Epidemiology of mental health problems among patients with cancer during COVID-19 pandemic. Transl. Psychiatry 2020, 10, 1-10. [CrossRef] [PubMed]

10. Barr, R.D.; Ferrari, A.; Ries, L.; Whelan, J.; Bleyer, W.A. Cancer in Adolescents and Young Adults. JAMA Pediatr. 2016, 170, 495-501. [CrossRef] [PubMed]

11. Košir, U.; Loades, M.; Wild, J.; Wiedemann, M.; Krajnc, A.; Roškar, S.; Bowes, L. The impact of COVID-19 on the cancer care of adolescents and young adults and their well-being: Results from an online survey conducted in the early stages of the pandemic. Cancer 2020, 126, 4414-4422. [CrossRef]

12. YACPRIME: A Study to Incite Change; Young Adult Cancer Canada (YACC): 2019. Available online: https://youngadultcancer. ca/yacprime/ (accessed on 12 May 2021).

13. Harris, P.A.; Taylor, R.; Thielke, R.; Payne, J.; Gonzalez, N.; Conde, J.G. Research electronic data capture (REDCap)—A metadatadriven methodology and workflow process for providing translational research informatics support. J. Biomed. Inform. 2009, 42, 377-381. [CrossRef] [PubMed] 
14. Benjamini, Y.; Hochberg, Y. Controlling the False Discovery Rate: A Practical and Powerful Approach to Multiple Testing. J. R. Stat. Soc. Ser. B Stat. Methodol. 1995, 57, 289-300. [CrossRef]

15. Thompson, C.G.; Kim, R.S.; Aloe, A.M.; Becker, B.J. Extracting the Variance Inflation Factor and Other Multicollinearity Diagnostics from Typical Regression Results. Basic Appl. Soc. Psychol. 2017, 39, 81-90. [CrossRef]

16. R Core Team. R: A Language and Environment for Statistical Computing; R Foundation for Statistical Computing: Vienna, Austria, 2021; Available online: https:/ / www.R-project.org/ (accessed on 13 May 2021).

17. Hsieh, H.F.; Shannon, S.E. Three approaches to qualitative content analysis. Qual. Health Res. 2005, 15, 1277-1288. [CrossRef]

18. Dedoose Version 8.3.47, Web Application for Managing, Analyzing, and Presenting Qualitative and Mixed Method Research Data (2021). SocioCultural Research Consultants LLC: Los Angeles, CA, USA. Available online: www.dedoose.com (accessed on 13 May 2021).

19. Kolb, S. Grounded Theory and the Constant Comparative Method: Valid Research Strategies for Educators. JETERAPS 2016, 3, 83-86.

20. Lou, E.; Teoh, D.; Brown, K.; Blaes, A.; Holtan, S.G.; Jewett, P.; Parsons, H.; Mburu, E.W.; Thomaier, L.; Hui, J.Y.C.; et al. Perspectives of cancer patients and their health during the COVID-19 pandemic. PLoS ONE 2020, 15, e0241741. [CrossRef]

21. Chen-See, S. Disruption of cancer care in Canada during COVID-19. Lancet Oncol. 2020, 21, e374. [CrossRef]

22. Papautsky, E.L.; Hamlish, T. Patient-reported treatment delays in breast cancer care during the COVID-19 pandemic. Breast Cancer Res. Treat. 2020, 184, 249-254. [CrossRef]

23. Holland, K.M.; Jones, C.; Vivolo-Kantor, A.M.; Idaikkadar, N.; Zwald, M.; Hoots, B.; Yard, E.; D’Inverno, A.; Swedo, E.; Chen, M.S.; et al. Trends in US Emergency Department Visits for Mental Health, Overdose, and Violence Outcomes before and during the COVID-19 Pandemic. JAMA Psychiatry 2021, 78, 372. [CrossRef] [PubMed]

24. Rains, L.S.; Johnson, S.; Barnett, P.; Steare, T.; Needle, J.J.; Carr, S.; Taylor, B.L.; Bentivegna, F.; Edbrooke-Childs, J.; Scott, H.R.; et al. Early impacts of the COVID-19 pandemic on mental health care and on people with mental health conditions: Framework synthesis of international experiences and responses. Soc. Psychiatry Psychiatr. Epidemiol. 2020, 56, 13-24. [CrossRef] [PubMed]

25. Hendren, S.; Chin, N.; Fisher, S.; Winters, P.; Griggs, J.; Mohile, S.; Fiscella, K. Patients' Barriers to Receipt of Cancer Care, and Factors Associated with Needing More Assistance from a Patient Navigator. J. Natl. Med. Assoc. 2011, 103, 701-710. [CrossRef]

26. Kantamneni, N. The impact of the COVID-19 pandemic on marginalized populations in the United States: A research agenda. $J$. Vocat. Behav. 2020, 119, 103439. [CrossRef]

27. Cameron-Blake, E.; Breton, C.; Sim, P.; Tatlow, H.; Hale, T.; Wood, A.; Smith, J.; Sawatsky, J.; Parsons, Z.; Tyson, K. Variation in the Canadian Provincial and Territorial Responses to COVID-19; University of Oxford: Oxford, UK, 2021; Available online: https:/ / centre.irpp.org/wp-content/uploads/sites/3/2021/03/Variation-in-the-Canadian-provincial-and-territorialresponses-to-COVID-19.pdf (accessed on 23 May 2021).

28. Hasson, S.P.; Waissengrin, B.; Shachar, E.; Hodruj, M.; Fayngor, R.; Brezis, M.; Nikolaevski-Berlin, A.; Pelles, S.; Safra, T.; Geva, R.; et al. Rapid Implementation of Telemedicine during the COVID-19 Pandemic: Perspectives and Preferences of Patients with Cancer. Oncologist 2021, 26, e679-e685. [CrossRef]

29. Ramaswamy, A.; Yu, M.; Drangsholt, S.; Ng, E.; Culligan, P.J.; Schlegel, P.N.; Hu, J.C. Patient Satisfaction with Telemedicine during the COVID-19 Pandemic: Retrospective Cohort Study. J. Med. Internet Res. 2020, 22, e20786. [CrossRef]

30. Mustafa, S.S.; Yang, L.; Mortezavi, M.; Vadamalai, K.; Ramsey, A. Patient satisfaction with telemedicine encounters in an allergy and immunology practice during the coronavirus disease 2019 pandemic. Ann. Allergy Asthma Immunol. 2020, 125, 478-479. [CrossRef]

31. Shaverdian, N.; Gillespie, E.F.; Cha, E.; Kim, S.Y.; Benvengo, S.; Chino, F.; Kang, J.J.; Li, Y.; Atkinson, T.M.; Lee, N.; et al. Impact of Telemedicine on Patient Satisfaction and Perceptions of Care Quality in Radiation Oncology. J. Natl. Compr. Cancer Netw. 2021, 1, 1-7.

32. Yoon, E.J.; Tong, D.; Anton, G.M.; Jasinski, J.M.; Claus, C.F.; Soo, T.M.; Kelkar, P.S. Patient Satisfaction with Neurosurgery Telemedicine Visits during the Coronavirus Disease 2019 Pandemic: A Prospective Cohort Study. World Neurosurg. 2021, 145, e184-e191. [CrossRef]

33. Monaghesh, E.; Hajizadeh, A. The role of telehealth during COVID-19 outbreak: A systematic review based on current evidence. BMC Public Health 2020, 20, 1-9. [CrossRef] [PubMed]

34. Berlin, A.; Lovas, M.; Truong, T.; Melwani, S.; Liu, J.; Liu, Z.A.; Badzynski, A.; Carpenter, M.B.; Virtanen, C.; Morley, L.; et al. Implementation and Outcomes of Virtual Care Across a Tertiary Cancer Center during COVID-19. JAMA Oncol. 2021, 7, 597-602. [CrossRef] [PubMed]

35. Latkin, C.A.; Edwards, C.; Davey-Rothwell, M.A.; Tobin, K.E. The relationship between social desirability bias and self-reports of health, substance use, and social network factors among urban substance users in Baltimore, Maryland. Addict. Behav. 2017, 73, 133-136. [CrossRef] [PubMed]

36. Tariq, S.; Woodman, J. Using mixed methods in health research. JRSM Short Rep. 2013, 4, 2042533313479197. [CrossRef] [PubMed] 